\title{
Test of the ITER TF Insert and Central Solenoid Model Coil
}

N. Martovetsky, M. Takayasu, J. Minervini, T. Isono, M. Suginoto, T. Kato, K. Kawano, N. Koizumi, H. Nakajima, Y. Nunoya, K. Okuno, H. Tsuji, M. Oshikiri, M. Mitchell, Y. Takahaski, S. Egorov, I. Rodin, R. Zanino, L. Savoldi, K. Arai, A Ninomiya

This article was submitted to 2002 Applied Superconductivity Conference, Houston, TX, August 4-9, 2002

July 29, 2002 


\section{DISCLAIMER}

This document was prepared as an account of work sponsored by an agency of the United States Government. Neither the United States Government nor the University of California nor any of their employees, makes any warranty, express or implied, or assumes any legal liability or responsibility for the accuracy, completeness, or usefulness of any information, apparatus, product, or process disclosed, or represents that its use would not infringe privately owned rights. Reference herein to any specific commercial product, process, or service by trade name, trademark, manufacturer, or otherwise, does not necessarily constitute or imply its endorsement, recommendation, or favoring by the United States Government or the University of California. The views and opinions of authors expressed herein do not necessarily state or reflect those of the United States Government or the University of California, and shall not be used for advertising or product endorsement purposes.

This is a preprint of a paper intended for publication in a journal or proceedings. Since changes may be made before publication, this preprint is made available with the understanding that it will not be cited or reproduced without the permission of the author.

This work was performed under the auspices of the United States Department of Energy by the University of California, Lawrence Livermore National Laboratory under contract No. W-7405-Eng-48.

This report has been reproduced directly from the best available copy.

Available electronically at http://www.doc.gov/bridge

Available for a processing fee to U.S. Department of Energy And its contractors in paper from

U.S. Department of Energy

Office of Scientific and Technical Information

P.O. Box 62

Oak Ridge, TN 37831-0062

Telephone: (865) 576-8401

Facsimile: (865) 576-5728

E-mail: reports@adonis.osti.gov

Available for the sale to the public from

U.S. Department of Commerce

National Technical Information Service

5285 Port Royal Road

Springfield, VA 22161

Telephone: (800) 553-6847

Facsimile: (703) 605-6900

E-mail: orders@ntis.fedworld.gov

Online ordering: http://www.ntis.gov/ordering.htm

\section{OR}

Lawrence Livermore National Laboratory Technical Information Department's Digital Library

http://www.llnl.gov/tid/Library.html 


\title{
Test of the ITER TF Insert and Central Solenoid Model Coil
}

\author{
N. Martovetsky, M. Takayasu, J. Minervini T. Isono, M. Sugimoto, T. Kato, K. Kawano, N. \\ Koizumi, H. Nakajima, Y. Nunoya, K. Okuno, H. Tsuji, M. Oshikiri, N. Mitchell, Y. Takahashi, S. \\ Egorov, I. Rodin, R. Zanino, L. Savoldi, K.Arai, A. Ninomiya
}

\begin{abstract}
The Central Solenoid Model Coil (CSMC) was designed and built by ITER collaboration between the European Union, Japan, Russian Federation and the United States in 1993-2001. Three heavily instrumented insert coils have been also built for testing in the background field of the CSMC to cover a wide operational space. The TF Insert was designed and built by the Russian Federation to simulate the conductor performance under the ITER TF coil conditions. The TF Insert Coil was tested in the CSMC Test Facility at the Japan Atomic Energy Research Institute, Naka, Japan in SeptemberOctober 2001. Some measurements were performed also on the CSMC to study effects of electromagnetic and cooldown cycles. The TF Insert coil was charged successfully, without training, in the background field of the CSMC to the design current of $\mathbf{4 6}$ $k A$ at $13 T$ peak field. The TF Insert met or exceeded all design objectives, however some interesting results require thorough analyses. This paper presents the overview of main results of the testing - magnet critical parameters, ac losses, joint performance, effect of cycles on performance, quench and thermo-hydraulic characteristics and some results of the posttest analysis.
\end{abstract}

Index Terms - Cable-in-Conduit conductors, measurements, losses, superconductor magnets.

Manuscript received August 5, 2002. This Work supported by governments of Japan, Russian Federation and European Community, by the US Department of Energy under contract to the Lawrence Livermore National Laboratory (contract No. W-7405-Eng-48) also under MIT Grant No. DE-FC02-93ER54186-D\&T.

Author N.M. is with Lawrence Livermore National Laboratory, Livermore, CA 94550 USA (telephone: (925) 4224269 , e-mail: martovetskyl@llnl.gov).

J.M., M.T., are with MIT Plasma Science and Fusion Center, Cambridge MA 02139, USA.

T.I., M.S., T.K., K.K., N.K, H.N., Y. N., K.O., H.T., M.O, are with Japan Atomic Energy Research Institute, Naka-machi, Ibaraki-ken, Japan,

N.M., Y.T. , . are with ITER International Team, Naka-machi, Ibarakiken, Japan

S.E., I.R. are with Efremov Institute of Electro-Physical Apparata, St. Petersburg, Russia

R. Z., L. S. are with Politecnico, Torino, 10129 Italy.

K. A. is with National Institute of Advanced Science and Technology , 11-1 Umezono, Tsukuba-shi, Ibaraki-ken, 305-8568, Japan

A. N. is with Seikei University, 3-3-1 Kitamachi, Kichijyoji, Musashinoshi, Tokyo, 180-8633, Japan.

\section{INTRODUCTION}

$T$ HE TF INSERT was built to verify performance of the ITER TF conductor in conditions relevant for the ITER TF magnet system. The details of the TF Insert design are given in [1]. It featured low coefficient of thermal expansion (CTE) conduit to allow maximizing the superconducting properties of the $\mathrm{Nb3Sn}$ strands, which are stress sensitive and lose critical current significantly in stainless steel conduit. The conduit material was Russian titanium alloy BT-1-0, which is equivalent to the commercially pure titanium. The preformed and heat treated thin wall conduit conductor was placed in the stainless steel cylinder from inside (see Fig. 1).

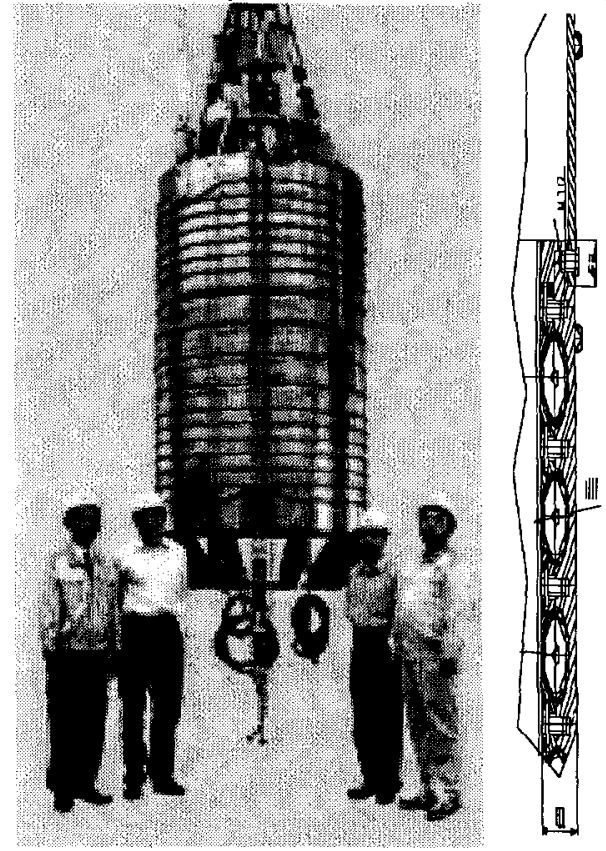

Fig. 1. TF Insert and a fragment of its cross section

In Fig. 1 one can see the cross section of the supporting cylinder with machined grooves, made of stainless steel, the CICC, placed in the grooves and bolted clamps on the ID of the Insert. The total length of the TF conductor was $43 \mathrm{~m}$. The conductor was insulated with glass tape, impregnated 
with epoxy resin and cured. A cooling tube was welded to the outside of the TF Insert mandrel as shown in Fig.1.

After cooldown the residual strain on the strands in the cable was expected to be about $-0.3 \%$ and after energizing to $46 \mathrm{kA}$ in $12 \mathrm{~T}$, the strain was expected to be $-0.2 \%$. If stainless steel conduit was used, the cooldown strain would have been expected to be about $-0.7 \%$ and at $12 \mathrm{~T}, 46 \mathrm{kA}$, the strain would have been $-0.6 \%$. In $12 \mathrm{~T}$, the critical current at $-0.25 \%$ strain is about $30-40 \%$ higher than that at $-0.6 \%$.

Thus, using titanium conduit was expected to provide a significantly lower thermal strain and therefore intended to ensure minimal degradation of superconducting properties.

In contrast to the CS Insert [2] or the Toroidal Field Model Coil (TFMC) [3], the TF insert had six temperature sensors installed on the conductor and many voltage taps to provide more details about behavior of the CICC (cable-in-conduit conductor) along the conductor length.

\section{DC PERFORMANCE OF THE TF INSERT}

\section{A. $\quad \mathrm{Nb}_{3} \mathrm{Sn}$ strand properties}

Knowledge of the strand data is a very essential part of the test result analysis, since the main question of the testing is how much basic strand properties can be realized in the CICC coil during full load operation. Since strand measurements are carried out in different conditions than the coil, it is important to generate an accurate correlation of the strand and CICC properties to compare the $\mathrm{CICC}$ performance against the strand. The $\mathrm{Nb}_{3} \mathrm{Sn}$ strand for the TF Insert was fabricated by Bochvar Institute of Inorganic Materials, Moscow, Russia. Extensive measurements of the strands showed a relatively low scatter of properties [4]. The Ic was measured on many samples, which underwent different fabrication steps. The noncopper $\mathrm{J}_{\mathrm{c}}(12 \mathrm{~T}, 4.2 \mathrm{~K})$ of strands from different batches varied from 550 to $650 \mathrm{~A} / \mathrm{mm}^{2}$ and more than $80 \%$ fell within 570 $630 \mathrm{~A} / \mathrm{mm}^{2}$. Seventeen samples taken from a strand along the $400 \mathrm{~m}$ length showed $\mathrm{J}_{\mathrm{c}}$ from 580 to $590 \mathrm{~A} / \mathrm{mm}^{2}$ indicating very good consistency of properties along the length. To study effect of CICC fabrication, seven strand samples were extracted from a CICC piece cut from the end of the TF Insert conductor after CICC fabrication. These samples were heat treated according to the specifications and $\mathrm{J}_{\mathrm{c}}$ was measured. They showed $J_{c}$ from 550 to $600 \mathrm{~A} / \mathrm{mm}^{2}$. Eleven strand witness samples were heat treated with the TF Insert [4]. All these samples showed critical current densities at $12 \mathrm{~T}$ and at $4.2 \mathrm{~K}$ between 569 and $593 \mathrm{~A} / \mathrm{mm}^{2}$.

The $\mathrm{N}$-value of the voltage-ampere characteristic (VAC) was also studied on the strands. The $\mathrm{N}$-value is determined from the approximation of the voltage growth versus current as:

$$
E=E_{\mathrm{c}}\left(\begin{array}{c}
I \\
T_{c}
\end{array}\right)^{N}
$$

where Ic is the critical current in the strand. Unfortunately, direct comparison of the strand properties to the CICC properties is complicated. The strands properties are most frequently measured from the $\mathrm{VAC}$ curves at $\mathrm{T}=$ const, while much higher currents in the CICC make such measurements difficult. For a CICC, T=const becomes impossible to implement at already modest levels of the voltage due to limited cooling capacity and a very high current. Therefore, for a CICC, voltage-temperature characteristics (VTC) are most frequently used at a fixed current. Thus, only one parameter (temperature) is variable, as opposed to two parameters (current and temperature) if the VAC is measured.

To take into account the temperature effect in VAC and deduce $\mathrm{N}$-value from non-isothermal measurements, one has to take into account the temperature dependence of the critical current such as:

$$
I_{c}(T)=I_{c}\left(T_{c s}\right)+\left(\frac{\partial I_{c}}{\partial T}\right)_{E} d T
$$

Then the experimental curves can be fit with the relationships (1-2) to find the best fitting parameter N. Here Tcs is the current sharing temperature defined by selected criteria of conventional "critical" electrical field, typically chosen at $10 \mu \mathrm{V} / \mathrm{m}$. A significantly simpler, but relatively less known, relationship to describe the low voltage part of the transition to the normal state is the following [8]:

$$
E=E_{c} \exp \left(\frac{I-I_{c}\left(T_{s c}\right)}{I_{o}}+\frac{T-T_{s c}}{T_{o}}\right)
$$

where relations between Io, To and $\mathrm{N}$ could be expressed as follows:

$$
\begin{aligned}
& I_{o}=T_{o}\left(\frac{\partial I}{\partial T}\right)_{E} \\
& N=\frac{I_{c}\left(T_{s c}\right)}{I_{o}}
\end{aligned}
$$

These relationships allow comparing on equal basis the data from different laboratories, where different correlations are used. Although the power law formula (1) is not strictly equivalent to the exponential law (3), these two relationships are very close over a wide range of voltages (3-4 orders of magnitude) and therefore practically indistinguishable.

It was noticed in recent experiments with $\mathrm{Nb}_{3} \mathrm{Sn} \mathrm{CICC}$ that the transition into the normal state of CICC is significantly broader than a transition of individual strands [2], [6]. Fig. 2 shows results of the $\mathrm{N}$-value measurements on the strand used in the TF Insert. The $\mathrm{N}$-value dependence on $\mathrm{T}, \mathrm{B}, \mathrm{I}, \varepsilon$ was measured methodically in some studies $[8,10]$, however no correlation was proposed for the $\mathrm{N}$-value. It was noticed [7] that many of the $\mathrm{Nb}_{3} \mathrm{Sn}$ strands studied in the ITER strand development program show a good correlation between the $\mathrm{N}$ factor and the critical current Ic(T,B_), at a given electrical field and strain, regardless of the temperature and magnetic field combination [7]. As one can see in Fig. 2, the Bochvar strand also show a good correlation between the $\mathrm{N}$-value and Ic $\mathrm{V} / \mathrm{m})$.

(1e-6 


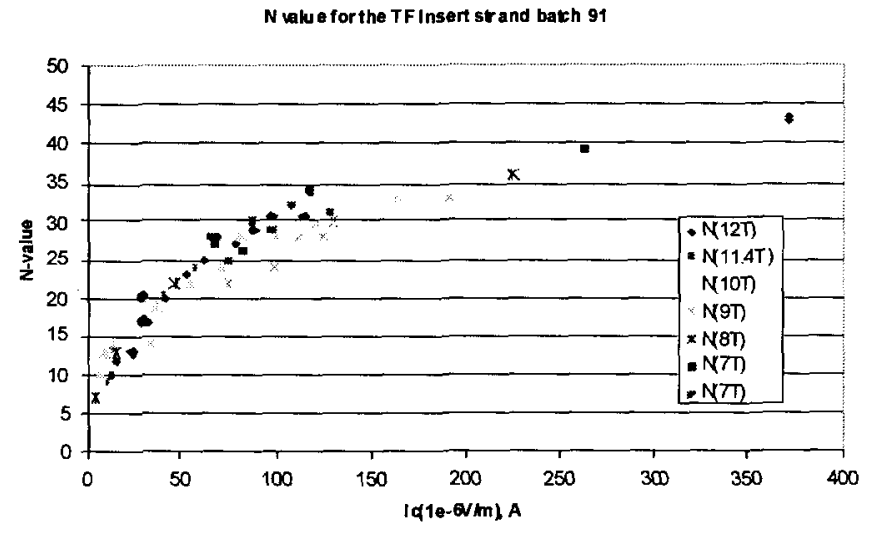

Fig. 2. Measurements of N-value on the TF Insert strand

Thus, the properties of the strands were well defined; good correlations were found for the strand Ic and $\mathrm{N}$-value versus field, strain and temperature for comparative analysis with the CICC performance.

\section{B. Ic and Tcs measurements of the TF Insert}

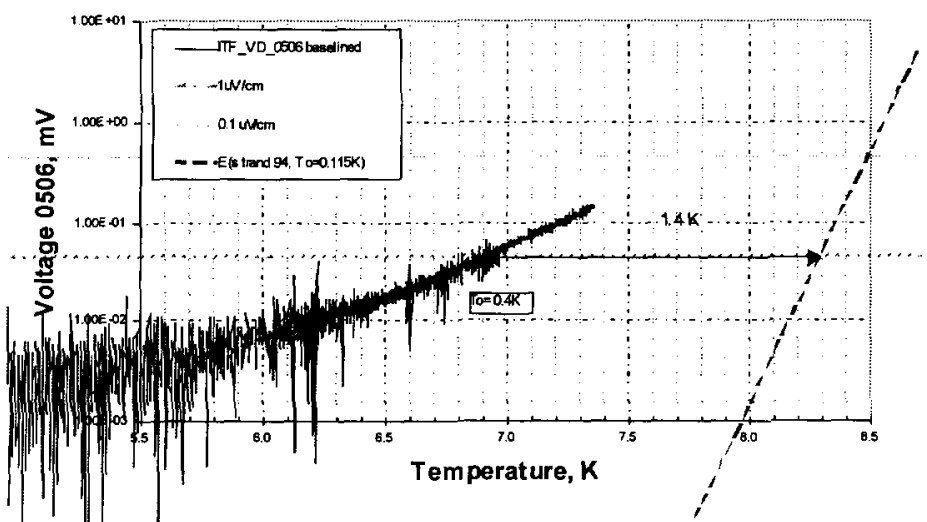

Fig.3. Voltage-temperature characteristic of the TF Insert and comparison with the Bochvar strand transition $(46 \mathrm{kA}, 12 \mathrm{~T})$

In the TF Insert measurements we paid attention to phenomena we discovered in a previous test campaign of the CS Insert [2], namely: reduction of the Ic, Tcs, and N-value in the cable in comparison with the strand $\mathrm{N}$-value apparently due to cycling loads.

Figure 3 shows a typical voltage-temperature characteristic of the TF Insert. The voltage is taken over approximately 4.5 $\mathrm{m}$ length of conductor. It indicates that the Tcs of the CICC is significantly lower than the Tcs of the strand at the same current per strand. It also illustrates that the $\mathrm{N}$-value of the TF Insert is significantly lower than the $\mathrm{N}$-value measured from the strand. This follows from comparison of the To parameters for two critical electric field criteria as shown in Fig.3. It is clear that the TF Insert showed noticeable degradation and reduction of the $\mathrm{N}$-value, qualitatively similar to what was observed on the CS Insert conductor. Because of the relatively smooth dependence of the voltage versus temperature, it is unlikely, that nonuniform current distribution in the cable plays any significant role at voltage levels of a few $\mu \mathrm{V} / \mathrm{m}$ and higher. This conclusion was obtained independently in [7] and [9] for similar CS Insert data. That leads to the conclusion that the low $\mathrm{N}$-value results from the change of strands intrinsic properties, not strand interactions in the cable. In other words, some factors in fabrication, cooldown and electromagnetic loading resulted in reduction of critical current of individual strands and their $\mathrm{N}$-value.

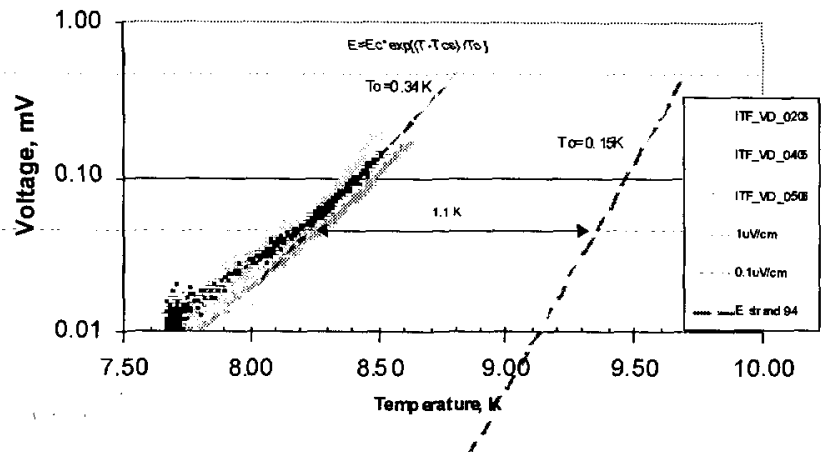

Fig. 4. Comparison of voltage-temperature characteristic of the TF Insert at different portions of the CICC along the length with the Bochvar strand performance $(11.4 \mathrm{~T}, 31.8 \mathrm{kA})$

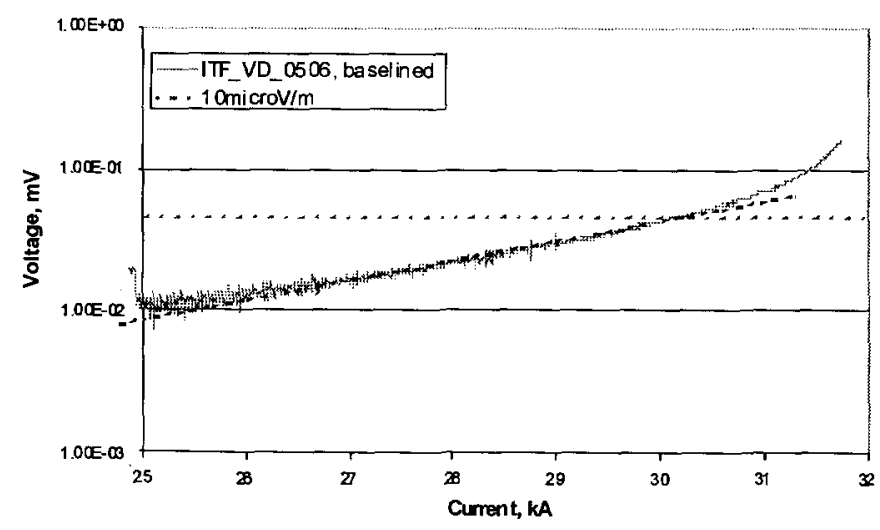

Fig. 5. VAC at $11.4 \mathrm{~T}$ at inlet temperature of $8 \mathrm{~K}$. TF Insert $\mathrm{N}=8.3$, original strand $\mathrm{N}=16$

Fig. 4 shows a VTC measured at $11.4 \mathrm{~T}$ and $31.8 \mathrm{kA}$. Again, a degradation and lower $\mathrm{N}$-value (To value is higher) are seen, although the degradation at lower magnetic field and at lower current is lower than degradation at higher field and current shown in Fig. 3. This observation may be useful for analyzing the TFMC test results tested in TOSKA facility at FZK ITP, Karlsruhe. The TFMC was tested at 7.24 $\mathrm{T}$ and its performance needs to be projected to $12 \mathrm{~T}$ operation.

Figure 4 also presents the signals from three different $4.5 \mathrm{~m}$ long portions of the conductor. The difference between these signals is relatively small, which shows that the consistency of the conductor properties along the length is good and that effect of the joints does not generate non-uniformity in current distribution at least at voltages corresponding to $10 \mu \mathrm{V} / \mathrm{m}$ in the center at relatively high currents.

Comparing the VTC of these three portions of the TF Insert we see some more rapid growth of the voltage in the 
downstream part of the conductor (sensors 02-03), starting from about $0.045 \mathrm{mV}$ per $4.5 \mathrm{~m}$ of the conductor length or at electrical field of $10 \mu \mathrm{V} / \mathrm{m}$. This effect is explained by selfheating of the conductor by heat generation due to resistive voltage development, presumably downstream from the temperature sensor. It also was noticed that after approximately $30 \mu \mathrm{V} / \mathrm{m}$ in the TF Insert center, the thermal run away at $40 \mathrm{kA}$ or higher becomes practically inevitable and could be prevented only by fast current discharge. Thus, electrical fields achievable in the strands (up to several hundreds of $\mu \mathrm{V} / \mathrm{m}$ ) could not be achieved for the CICC due to thermal ran away.

Since $\mathrm{N}$-value is different in the strand and the CICC, the degradation cannot be expressed in a simple way: it is less at higher electrical fields but if the electrical field is too high, it cannot be achieved in practice in a stable fashion in steady state conditions.

One of the few VAC measured in the TF Insert is shown in Fig. 5. The $\mathrm{N}$-value of the VAC in Fig. 5 is 8.3 to be compared with original strand $\mathrm{N}=15-16$. Figure 5 also illustrates a large deviation from linear function in semilogarithmic coordinates due to self-heating starting from about $15 \mu \mathrm{V} / \mathrm{m}$.

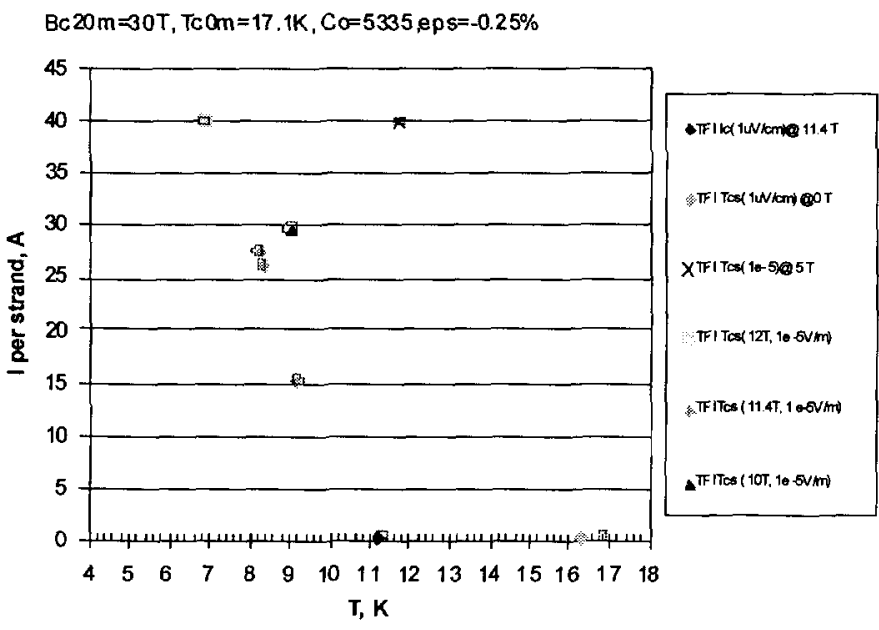

Fig. 6. Comparison of measurements (solid symbols) and correlation (open circles) of the TF Insert Ic and Tcs data

The non-isothermal effects become apparent above $10 \mu \mathrm{V} / \mathrm{m}$ in the center, which emphasizes that the measurements of VAC are less convenient than VTC for large conductors where selfheating becomes a factor.

The DC measurements on the TF Insert could be described by a correlation proposed by Summers [11]. This is illustrated in Fig. 6 where the correlation accuracy is very good except for the zero field measurement, which is thought to be a not very reliable measurement due to high temperature and strong heat transfer between the conductor and the mandrel.

This correlation allows us to compare the TF Insert performance with the strand as shown in Fig. 7 at $12 \mathrm{~T}$ and 10 $\mu \mathrm{V} / \mathrm{m}$.

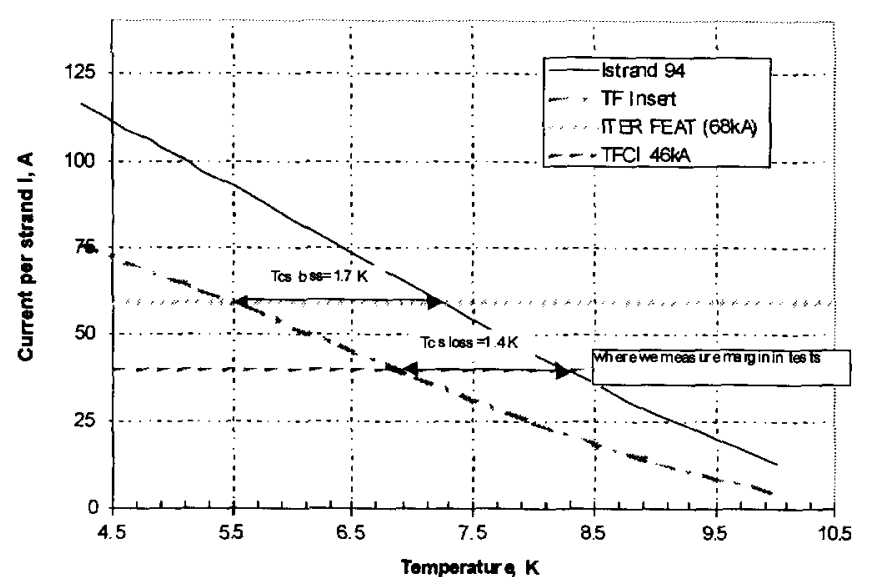

Fig.7. Comparison of TF Insert performance versus Bochvar strand at $12 \mathrm{~T}$ at $10 \mu \mathrm{V} / \mathrm{m}$ and $-0.25 \%$.

A noticeable reduction of the critical current in the TF Insert is obvious. However, the TF Insert and other Inserts in the ITER Model Coil program were designed with a $2 \mathrm{~K}$ temperature margin from the operating point. Thus, loss of 1.4 or $1.7 \mathrm{~K}$ of the temperature margin would not prevent the TF system from completely fulfilling the design parameters for ITER as it was defined in the Final Design Report of 1998. On the other hand, since the current ITER design [13] changed its parameters from 1998 for a lower temperature margin, the loss of temperature margin may threaten achieving the operating point. The mechanisms of degradation need to be understood better and methods of mitigation explored.

The maximum achievable current in the TF Insert was 46 $\mathrm{kA}$ due to facility limitations. If one would extrapolate operation of the TF conductor to $12 \mathrm{~T}$ at $68 \mathrm{kA}$, or $60 \mathrm{~A}$ per strand, as it is planned for the ITER FEAT magnets, the loss in the Tcs would have been $1.7 \mathrm{~K}$. Comparison with ITER FEAT requires some explanation. Even though ITER FEAT TF conductor will use thinner strands with higher current density than those used for the TF Insert, the critical current is about the same, which makes comparison to ITER FEAT parameters valid, assuming that the degradation pattern remains the same. The reasons for the degradation have not been resolved yet. It is unlikely that a non-uniform current distribution initiated by joints plays any role, since we did not see large distortions on VAC or VTC curves, which normally indicate non-uniform distribution problems. Also, the longitudinal voltage in the CICC is much larger than the voltage across the joints and therefore their petals and subcables. Thus it is very unlikely that this high voltage would not suppress all non-uniformity in the subcable resistances. There may be two other possible explanations: damage during fabrication or damage due to electromagnetic forces. The intention of using the titanium conduit was to see how much advantage a low CTE conduit can give to a TF conductor in comparison with a stainless steel conduit type $316 \mathrm{~L}$ or similar. If one would try to express the degradation in terms of compressive strain equivalent, then to bring the strand properties to the conductor one has to assume 
approximately $-0.6 \%$ strain. Taking into account that under $46 \mathrm{kA}$ and $12 \mathrm{~T}$ the electromagnetic strain is about $0.1 \%$, it would mean that the cooldown strain in the TF Insert needs to be $-0.7 \%$ to explain the degradation. Many experiments with stainless steel conduit (see [12] for example) showed that stainless steel conduit and stainless steel structure generate the cooldown compressive strain about $-0.7 \%$. This means that the TF Insert with titanium conduit behaved approximately as a CICC with a stainless steel conduit with no degradation other than natural compressive strain. In other words, the TF Insert did not utilize the advantages of the low CTE thinwalled conduit. On the other hand, if the TF Insert would have been made with a stainless steel conduit, the degradation could have been worse.

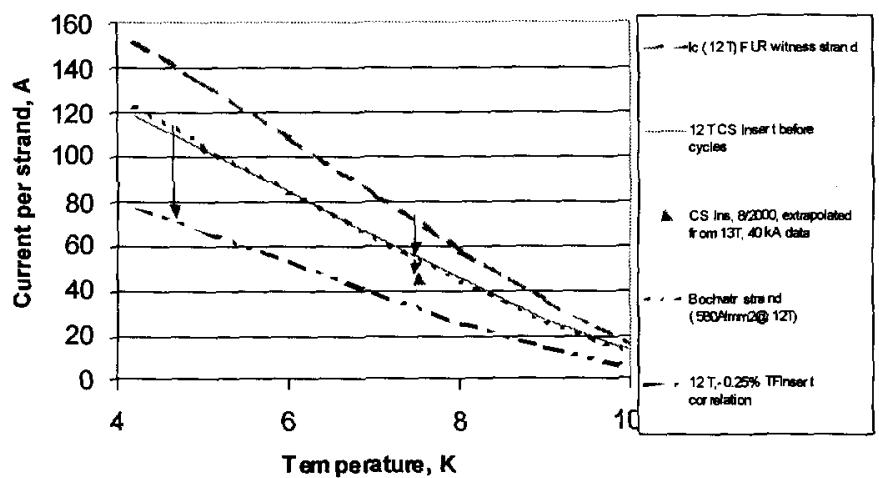

Fig. 8. Performance of the TF and CS Insert in $12 \mathrm{~T}$ at $10 \mu \mathrm{V} / \mathrm{m}$ versus their witness strand properties

Figure 8 shows a comparison of the TF Insert to CS Insert performance and their comparison to the original strand properties in terms of $I_{c}(T)$ per strand. The long dash curve shows the $I_{c}(T)$ of the Furukawa strand, used in the CS Insert and heat treated with the CS Insert, so-called strand witness. Its critical current is significantly higher (15-20\%) than the properties measured in the production QA tests, presumably due to much longer heat treatment used for the CS Insert than for the production QA tests. The CS Insert performance in 12 $\mathrm{T}$ is shown by a solid line curve, which is an extrapolation from measured CS Insert properties at $13 \mathrm{~T}$. A short dashed line shows an average Bochvar strand $I_{c}(T)$ in $12 T$. It practically coincides with the CS Insert $I_{c}(T)$. A dash-double dot curve shows performance of the TF Insert. The triangle shows extrapolated Ic $(T, 12 T)$ for the CS Insert after cycles and quenches.

The TF Insert degradation is slightly larger than the CS Insert degradation after cycles/quenches. Also, as it will be discussed below, the TF Insert did not show noticeable change in properties after cycles and quenches. This result gives important information about the safety margin from the single strand property, which needs to be taken into account for a magnet design.

\section{Effect of cycles and quenches on the DC properties in the TF Insert}

The TF Insert was subjected to 1000 cycles with a loading to $14 \mathrm{kA}$, which simulated mechanical conditions of the TF conductor in ITER operation. After the cycles several Tcs measurements were performed to trace the TF Insert properties. Later another 1000 cycles were given to the TF in $12 \mathrm{~T}$ to study the effect of cycling on the TF Insert properties. This time the amplitude of the current was $36 \mathrm{kA}$. After quench initiations with $5 \mathrm{~s}$ and $7 \mathrm{~s}$ of the delay between beginning of the normal zone propagation and discharging the TF Insert onto the dump resistor, we measured to determine if quenches affected the Tcs. In the previous test campaign with the CS Insert we discovered that quenches and cycles affected the Tcs by almost $0.5 \mathrm{~K}$, but we did not have unambiguous evidence whether cycles or quenches caused these changes. Some indirect indications suggested that the CS Insert degradation occurred due to quenches since, most of the degradation happened always when quenches were involved. When there were no quenches, but cycles only, we did not measure any noticeable change in the Tcs. But this observation is not a definite proof that quenches were responsible for degradation in operation. There is still a possibility that cycling load cause degradation in a non-monotonic fashion. The CRPP experiments designed to study evolution of the CICC properties under cyclic loads revealed that the $\mathrm{N}$-value and the Ic at $10 \mu \mathrm{V} / \mathrm{m}$ dropped down in a subscale conduit [6] due to cycles in more or less monotonic fashion and after several hundreds of cycles a saturation was reached.

In the TF Insert testing campaign we were monitoring the Tcs after cycles and quenches, hoping to reveal the mechanism of degradation in large CICC. Results of the transition evolution after cycles and quenches in the TF Insert for the central voltage taps 05-06 are shown in Fig.9. Similar behavior was detected for other voltage taps along the whole length of the conductor.

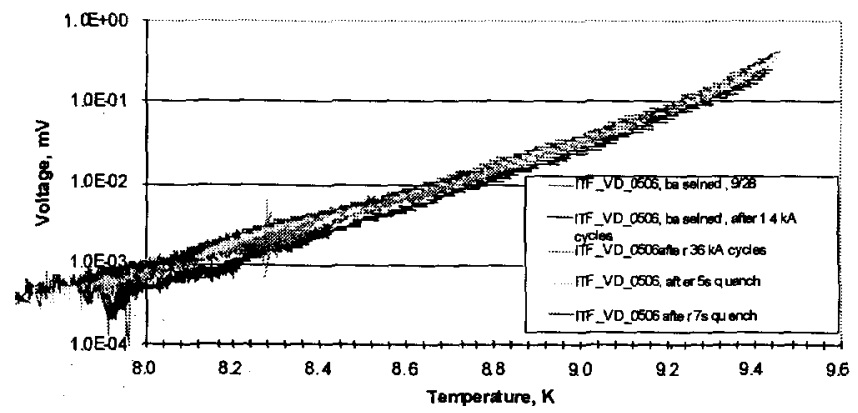

Fig.9. Evolution of the Tes in $11.4 \mathrm{~T}, 17.6 \mathrm{kA}$ after cycles and quenches

The change of $50-70 \mathrm{mK}$ is within the practical accuracy of our measurements. Therefore the change in the TF properties is different than what was observed on the CS Insert or CRPP sample. It indicates that there is no "universal" mechanism of the CICC properties evolution. Some NbSn CICC may be free from degradation due to cycling or quenches. Since degradation of properties is a very serious threat to the performance and may require larger safety margins, the mechanisms of the degradation need to be studied in more detail. 


\section{JOINT PERFORMANCE}

The joints for the TF Insert were made by the Efremov Institute similar to the CSMC lap joints [14]. Indium wires were placed at the interface between the sleeves and were crushed under compression, thus forming an oxide free contact. This technique was used on dismountable joints of the CSMC [2] and showed that such joints resistance is comparable to the soldered joints. The TF Insert joints demonstrated a low resistance $(0.8$ to $1.3 \mathrm{nOhm}$ at $46 \mathrm{kA})$ with weak dependence on transport current or applied field.

During the TF Insert test campaign the resistances of all joints in the CSMC were re-measured. No noticeable changes were found in comparison with the year 2000 test campaign [2], which verified a very robust and reproducible design of the joints, including butt joints developed by JAERI. Most of the joints had resistance between 1 and $2 \mathrm{nOhm}$ at $46 \mathrm{kA}$, which is within the specifications for the ITER magnet system.

\section{STABILITY AND NORMAL ZONE PROPAGATION}

Stability of the TF Insert was measured using an inductive heater on the conduit. Due to low resistivity of the conduit most of the energy from the inductive heater pulse was deposited into the conduit. The measurements showed that most of the available enthalpy of helium is utilized, which shows that the design of the TF conductor operates in a wellcooled regime.

The normal zone propagation was studied up to $7.2 \mathrm{~s}$ delay between the normal zone initiation and energy dump. The maximum temperature of the conductor was estimated to reach $160 \mathrm{~K}$. Since no noticeable change in CICC properties was observed, this result verifies that the design criteria of $150 \mathrm{~K}$ maximum hot spot temperature is an acceptable limit, which should not affect performance of the CICC. The velocity of the normal zone propagation grew in $7 \mathrm{sec}$ with acceleration from $0.2 \mathrm{~m} / \mathrm{s}$ to more than $2 \mathrm{~m} / \mathrm{s}$, with most of the growth occurring after $5 \mathrm{~s}$. This effect was not observed on the CS Insert, since the CS Insert did not go beyond $5 \mathrm{~s}$ delay times.

\section{CONCLUSION}

The TF Insert reached all the design objectives. It reached $46 \mathrm{kA}$ in $13 \mathrm{~T}$ with no training, which validated a thin conduit conductor in a grooved structure concept for ITER. Hydraulic characteristics, joint performance and hysteresis losses met or exceeded the design objectives. The TF Insert verified the design allowable of $150 \mathrm{~K}$ as a hot spot maximum temperature. The TF Insert demonstrated feasibility of Ti alloy as a conduit material for CICC.

The TF Insert showed noticeably lower properties in comparison with the single strand data: reduction of Tcs and Ic at $10 \mu \mathrm{V} / \mathrm{m}$ and significant reduction of the $\mathrm{N}$-value. These data are very valuable for selection of the safety margin for fusion magnets and will stimulate more detailed studies on the mechanisms of extrapolating single strand data to large $\mathrm{Nb}_{3} \mathrm{Sn} \mathrm{CICC}$ performance in a coil environment.

\section{ACKNOWLEDGMENT}

The authors are grateful to the Russian Federation home team for their dedicated work and successful completion of the TF Insert fabrication. We are grateful to the JAERI facility personnel for running the tests. We are grateful to the ITER community for fruitful discussions and analysis of the test results.

\section{REFERENCES}

[1] V. Glukhih, O. Filatov, V. Belyakov, et al "ITER TF conductor insert manufacturing," Presented at MT-17 conference, Geneva, Switzerland, September 2001.

[2] N. Martovetsky, P. Michael, J. Minervini et al, "ITER CS Model Coil and CS Insert test results" IEEE Tras. Applied Superconductivity, vol. 11, N1, pp. 2030-2033, March 2001.

[3] E. Salpietro "A Toroidal Fjeld model coil," Presented at MT-17 conference, Geneva, Switzerland, September 2001.

[4] E. Dergunova, A. Vorobieva, "Database of $\mathrm{Nb}_{3} \mathrm{Sn}$ strand for ITER" Presented at the meeting on TF Insert test results and analysis, Efremov Institute, St. Peterburg, February 2002, unpublished.

[5] N. Kozlenkova, A. Vorobieva, Test results of $\mathrm{Nb}_{3} \mathrm{Sn}$ strands for ITER, ibid

[6] P.Bruzzone, Performance evolution of NbSn cable-in-conduit conductors under cyclic load, Presented at MT-17 conference, Geneva, Switzerland, September 2001.

[7] N. Martovetsky, Assessment of the CS Insert Tcs data: how do we compare conductor performance to the strand and how we make interpretations, memorandum, $5 / 18 / 01$, unpublished

[8] G.L. Dorofeev, E.Yu. Klimenko, A.B. Imenitov, Cryogenics, 1980, v. 20,N6, p.307

[9] Arend Nijhuis and Yuri llyin, Current distribution: reconstruction from self-field measurements and impact on cable n-value, Report EFDA00/552, University of Twente, Netherlands, December 12, 2001.

[10] A. Godeke, H.J.G. Krooshoop, H.G. Knoopers et al, Wide temperature and field scaling relations in NbSn ITER strands, Report University of Twente, No. UT-NET/EFDA 2000-5, September, 2000

[11] L. T. Summers, M. Guinan et al, A Model for the Prediction of Nb3Sn Critical Current as a Function of Field, Temperature and Radiation Damage, IEEE Trans on Magnetics, 27(2), March 1991, 2041

[12] W. Specking, JL Duchateau, First Results of Strain Effects on Critical Current of Incoloy Jacketed $\mathrm{Nb}_{3} \mathrm{Sn}$ CICCs, Proceedings 15 th Int Conf on Mag Tech, Beijing, Oct, 1997

[13] ITER Final Design Report, Design Description Document: 1.1 Magnet, July 2001.

[14] N. Martovetsky, J. Jayakumar, R. Manahan, P.Michael et al., Development and Test of the ITER conductor joints for the central solenoid, Fusion Technology, ILLINOIS-0748-1896, 1998, v.34, No3,p.808-814. 